Transactions of the Geological Society of London

\title{
IX.--Additional Notices on the Fossil Genera Ichthyosaurus and Plesiosaurus.
}

WILLIAM D. CONYBEARE

Transactions of the Geological Society of London 1822, v.s2-1; p103-123. doi: $10.1144 /$ transgslb.1.1.103

$\begin{array}{ll}\begin{array}{l}\text { Email alerting } \\ \text { service }\end{array} & \begin{array}{l}\text { click here to receive free e-mail alerts when new articles cite } \\ \text { this article } \\ \text { Permission } \\ \text { request }\end{array} \\ \begin{array}{l}\text { click here to seek permission to re-use all or part of this article } \\ \text { Subscribe }\end{array} & \begin{array}{l}\text { click here to subscribe to Transactions of the Geological } \\ \text { Society of London or the Lyell Collection }\end{array}\end{array}$

\section{Notes}




\title{
IX.-Additional Notices on the Fossil Genera Ichthyosaurus and Plesiosaurus.
}

\author{
By the Rev. WILliaM D. CONYBEARE, m.G.s. \&c.
}

\author{
[Read May 3, 1822.]
}

IN the former communication which I had the honour of submitting to the Society, on the subject of the fossil remains of animals belonging to the Saurian order, it was my object to give a general outline of the facts which my own observation, or that of others, had enabled me, up to that period, to ascertain concerning the genus Ichthyosaurus; and to introduce to the knowledge of the public a new genus, which my own inquiries, assisted by those of Mr. De la Beche, had enabled me to constitute, and to which I appropriated the name of Plesiosaurus.

It is my present intention to redeem the pledge I gave of endeavouring to fill up the outlines which I then offered, so far as the additional facts gathered in the researches of another year, the examination of many new and illustrative specimens, and my correspondence with scientific friends, have enabled me to do so. Were I at liberty to acknowledge all my obligations to those friends, I should at once disclaim for myself a large share of any merit that may be supposed to be attached to the prosecution of these inquiries, and at the same time confirm the results I have to state by authority far superior to my own. And I wish it to be understood, that I have again received, throughout, the assistance of Mr. De la Beche, and continued to derive material information from the fresh specimens which have found their way into the collection of Colonel Birch.

\section{ICHTHYOSAURUS.}

The new materials which have been collected respecting this genus will enable me to lay before the Society an examination of many points concerning its structure, which before could be only generally stated; a description of some parts of the skeleton previously unascertained, particularly those connected with 
the back of the mouth and head; an attempt to discriminate the species of this genus ; and a fuller statement of the analogies which must determine its place among the different classes of lacertæ. I had originally, it will be remembered, compared it principally to the crocodile ; and after a very mature examination, I am still of opinion that the analogies between the Ichthyosaurus and that family are more striking and numerous, than those which connect it with the other tribes of Lacertæ. But to judge of the relative value of conflicting analogies is one of the most delicate and difficult points of comparative anatomy; and I shall throughout confine myself to stating simply those analogies, whatever may be their tendency, leaving those who may be more competent to such a task, to decide on the conclusions to be deduced from the whole evidence*

I need not repeat, what is fully agreed on all hands, that the Ichthyosaurus is an animal entirely sui generis; possessing, however, sufficient analogies with the Saurian order to justify our referring it to that great natural division. It is likewise agreed, that in respect of certain analogies, it is allied most nearly to the crocodilian branch, and in respect of others to the lacertian branch of that order: and the remaining question, to which of these it approximates most nearly, is one, after all, of very subordinate importance. Concerning this most material point, viz. that the animal was exclusively an inhabitant of the sea, no doubt has been expressed by any of those who have most attentively considered its structure.

It is very satisfactory to me to be able to state, that the progress of my inquiries, though it has afforded clearer views on many points, has scarcely in any material circumstance obliged me to alter those which $I$ have had the honour of laying before the Society on a former occasion. Some slight modifications will be found in the course of the following observations; but there are only two points which appear to require a more prominent notice;-

* It cannot be too often pressed on the zoological observer, that he must carefully keep in view the collective tendency of all the analogies presented by the subject before him : in no department of inquiry are we more liable to fall into error from hasty induction. To instance this in a recent animal, the Ophisaurus : were the head alone of this animal known, no person acquainted with comparative anatomy would hesitate to pronounce that it belonged to a Lacerta, and was connected with a body having regular quadrupedal extremities; yet in truth its body belongs to an entirely different system, being that of a regular Serpent. In the same manner in the fossil genus Ichthyosaurus, the head of a lacertian animal is joined to the vertebra of a fish and extremities entirely sui generis. Beautiful as is the doctrine of the laws of coexistence in the parts of animals, so admirably illustrated by Mr. Cuvier, it yet requires to be applied with all the caution so conspicuous in the writings of this naturalist, to render it a secure instrument of investigation. 
on the Fossil Genera Ichthyosaurus and Plesiosaurus.

First; in comparing the large holes behind the orbit in the ichthyosaurus with those in the crocodile, I ought to have noticed that they have a still closer analogy with the temporal fossæ in the other lacertæ. The use of the cavities in question in the skull of the crocodile not having been, at that time, clearly explained, and these cavities having been erroneously described as peculiar to that animal, an obscurity was thrown over the whole of this part of the subject. Subsequent information and my own further examination have satisfied me, that they are the true temporal fossæ of the crocodile, and do not differ, except in their smaller size, from those of the remaining lacertæ. The ichthyosaurus, in respect to this part, appears to hold an intermediate place between the crocodile and the lacertæ; but certainly approximates most nearly to the latter: so that thus far I must correct my former statements.

The second point to which $I$ am desirous of adverting, in limine, is the representation given of the roof of the mouth, in fig. 12. Pl. 40. Vol. V. I have reason to believe, from the examination of nearly perfect specimens since discovered (see PI. XVII. of the present volume), that the fractured state of the specimen from which the drawing for the former plate was taken, and also the irregular line of section it presented, have occasioned an exhibition of these parts in some respects incorrect.

The figures of the head of the ichthyosaurus, given in the former communication, were, in many instances, restorations made up from the comparison of many different specimens. Indeed, had not this method been adopted, it would have been impossible to communicate, without a large apparatus of engravings, the general information which alone it was my object, at that time, to impart. In my present communication I shall submit drawings from individual specimens only; a method far more satisfactory, where it is practicable within reasonable limits : and it will be seen that these figures fully confirm the restorations attempted in the preceding memoir.

In proceeding to the details which I now propose to offer, I shall consider,

I. The Dentition of the Ichthyosaurus.-In my former paper on this subject, following the authority of Sir Everard Home, I simply stated a general agreement with the dentition of the crocodile : but from the importance attached to this branch of the subject by most anatomical writers, I have since been induced to examine the matter more minutely; especially as I have found a disposition in some scientific friends, to whom my observations were communicated, to compare the dentition of the ichthyosaurus rather with that of the other lacerte. It will be necessary, in the first instance, to state in what points 
the dentition of the crocodile differs from that of the other members of the great Saurian family.

In the crocodile, the teeth are lodged loosely in distinct alveoli: they always remain hollow: the new tooth first appears as a germ on the inner face of the root of the old tooth, where, preventing the growth, it occasions a fissure; through which, as it continues to elongate itself, it penetrates into the hollow of the old tooth: and, lastly, by its increase it splits the old tooth, the fragments of which it causes to fall off. There being in the crocodile a continual succession of fresh teeth, and not a single change as in man (and as in most, $I$ believe, of the mammalia), the teeth are never filled up by the ossification of their pulpy interior, but always continue hollow:-and the process above described may be traced as going on in the jaws of crocodiles of all ages.

In the other lacertæ, on the other hand, the teeth are not lodged in alveoli, nor even in a continuous furrow; but the jaw bone presents only (if the expression may be allowed) a sort of parapet on the outer side; and the teeth are fixed to it by a bony mass occupying the place of their root, and incorporated organically both with the tooth and with the jaw bone. The new teeth make their first appearance, in cells, from within this osseous mass, and shoot irregularly through its substance, gradually producing a necrosis in it, and thus causing both the mass and the old teoth which it supports, to fall.

Finally, the tooth in these genera becomes completely solid, its interior cavity being filled up by the ossification of the pulpy substance; so that they do not appear to have many recurrences of fresh sets of teeth, and perhaps have only one.

The first two figures of Plate XV. represent the dentition of the crocodile ; the third, that of the fossil animal of Maestricht, which entirely agrees with the ordinary lacertian type. Let us proceed to institute a comparison between the teeth of these, and of the ichthyosaurus.

1st, The teeth of the ichthyosaurus are lodged loosely in a long continuous furrow, retained only, as it would appear, by the substance of the gum. This structure is widely different from that of the monitors and ordinary lacertæ, where the teeth adhere to the jaw by a solid bony union. It differs much less from that of the crocodile; the only variation being, that the alveoli (which in the crocodile are separate) here run together into one long continuous furrow ; -in which indeed the rudiments of a separation into distinct alveoli may be traced, in the slight ridges extending, between the teeth, along the sides and bottom of the furrow. (See PI. XV. fig. 12.) As corroborating this ana$\operatorname{logy}$, I am informed that, in the crocodile, the three or four posterior alveoli often run together into a continuous furrow, exactly in the same manner. 
on the Fossil Genera Ichthyosaurus and Plesiosaurus.

2dly, The appearance and progress of the new tooth, which is to replace the old one, is very nearly the same in the ichthyosaurus and in the crocodile. This will be best seen by comparing figs. 4,5 , and $6, \mathrm{Pl}$. XV. which represent the dentition of the former, with figs. 1 and 2 , which represent that of the latter. In fig. 4. is seen a tooth of an ichthyosaurus, in which a fissure has been effected in the side of the root, by the growth of the new tooth. In fig. 2, a crocodile's tooth under the same circumstances, an exact agreement will be observed in this respect. Fig. 5. represents a section passing longitudinally along the jaw, and exhibiting the new tooth, which has penetrated the interior cavity of the old one. Fig. 5, $b$, shows the appearance of the upper surface of this specimen, where the tops of the old and new tooth are broken off. Fig: 6. represents a similar section passing transversely across the jawbone. In this figure the jaw-bone itself and the canal which traverses it for the passage of the nerves and vessels are exhibited. These two figures may be compared with fig. 1 , which represents the appearance of the new tooth of the crocodile, when it has penetrated the interior cavity of the old one. The agreement will be found exact. But if a comparison be instituted with fig. 3, (representing the dentition of the fossil animal of Maestricht, and of the lacertæ distinguished by generic characters from the crocodile,) a great difference will be seen : for in these last two cases the new tooth, instead of shooting into the interior of the old one, shoots irregularly across the osseous mass, incorporating it with the jaw-bone.

It should be observed, that in all these instances the new tooth, when it first makes its appearance, consists only of a hollow conical shell of enamel, which increases in length by the apposition of osseous matter at the lower edge, gradually forming its root.

$3 \mathrm{dly}$, In pursuing, however, the history of the teeth of the ichthyosaurus to the last stage, we quit these analogies with the crocodile, and arrive at another point, wherein the ichthyosaurus resembles the other lacerta, in common with many of the mammalia. This is the gradual obliteration of the interior cavity in old age, by the ossification of the pulpy nucleus. Fig. 13. PI. XV. represents a transverse section of the root of a tooth, in which this process has taken place. The ossified pulp has become a spongy mass of reticulated bony fibres; and the osseous laminæ forming the exterior of the root, are seen surrounding it in wavy cortical layers; not, however, continuing all round the tooth, but interrupted by openings corresponding to the furrows that mark the outside of the tooth; between which openings the spongy substance insinuates itself. The only inference from this filling up of the interior cavity in 
the teeth of the ichthyosaurus is, that in this animal the succession of new sets of teeth was but seldom repeated, and perhaps not more than once.

II. Determination of the different Species of Ichthyosaurus from Their TeEth.-When we consider the different forms which the same bones are known to receive in the same animals at different ages, it is not possible to approach without hesitation so delicate a problem, as that of determining, from the teeth alone, the species of an animal, our knowledge of which depends entirely upon fossil remains, often mutilated and obscure. Mr. De la Beche, however, long since believed himself able, from the examination of the teeth, combined with some other characters, to establish three species, to which he has applied the names communis, platyodon, and tenuirostris : and to these our joint observations have recently added a fourth, Ichthyosaurus intermedius. All these occur in the formation of lias. The ichthyosaurus whose remains are found in the Kimmeridge clay, appears to belong to yet another species : but our knowledge of its structure is not yet sufficiently precise, to enable us to describe it. We have not seen its teeth; and its distinctive characters depend, at present, on its cervical vertebræ.

The distinctions of teeth in the first four species above enumerated are as follows : (see Pl. XV.)

1. I. communis. (fig. 8.) Upper part of the tooth conical, not very acute, slightly aduncate, and thickly covered with prominent longitudinal striæ.

2. I. platyodon. (fig. 7.) Upper part of the tooth smooth and flattened, so as to present sharpened edges. (See transverse section at c. fig. 7.)

3. I. tenuirostris. (fig. 10.) In this the teeth are much more slender than in the preceding species. But the species is best marked by the extreme length and thinness of the snout, in which points it very strikingly exceeds all the other ichthyosauri.

4. I. intermedius. (fig. 9.) The upper part of the teeth is much more acutely conical than in $\mathbf{I}$. communis, and the striæ less prominent : yet they are less slender than in I. tenuirostris. This species is also distinguished by differences (presently to be noticed) in the angular and coronoid bones of the lower jaw.

The specimens of I. platyodon are generally large : the most gigantic yet discovered are referable to this species. The specimens of $I$. communis occur of very different sizes; such as may have belonged to animals from five to fifteen feet in length when entire. Those of I. tenuirostris and I. intermedius appear not to exceed one half the largest size of I. communis :-these last observations, however, are offered with much diffidence, as it must be ob- 
on the Fossil Genera Ichthyosaurus and Plesiosaurus.

viously impossible to obtain from the examination of a few individuals a certain determination of the size of the species when full grown.

III. Structure or the Lower $\mathbf{J}_{\mathbf{A w}}$.-In order to indicate more clearly the analogies of the ichthyosaurus in this part of its structure, I shall compare each of the bones of its lower jaw with the corresponding bones both of the crocodile and of the other lacertæ.

1. The Dental bone.-The furrow which contains the teeth, exhibiting in the slight ridges that traverse it the rudiments of a division into distinct alveoli, approximates (as has been seen) much more nearly to the analogous part in the crocodile, than to that in the other lacerta. See fig. 12. PI. XV.

Another circumstance, however, has an opposite bearing: namely, the distribution of the holes on the outside of its anterior portion, which convey the branches of the inferior maxillary nerve and vessels. These in the crocodile exhibit a series of small dots irregularly dispersed; in the other lacertæ and in the ichthyosaurus they appear as a regular row of conspicuous perforations. See fig. 12. PI. XV. and fig. 6. Pl. XVI.

The ichthyogaurus has eight or nine of these perforations, branching out laterally from the canal which runs longitudinally through the substance of the dental bone. The posterior branches are inflected backwards, the anterior forwards. As these branches are sent out from the central canal to the exterior, so there are others directed to the interior, to supply the teeth. Fig. 12. Pl. XV. exhibits a portion of the dental bone, partly cut away, in order to expose this central canal and its branches. The same thing is also shown in Pl. XVI. fig. 6.- and in the section, fig. 1.

2. The Angular bone. 3. The Coronoid bone. and 4. The Crescent-shaped bone.-The structure of all these bones is essentially connected with the disposition of the muscles moving the lower jaw ; namely, the temporal, the masseter, and the pterygoid muscles. The crocodile in these respects exhibits a peculiar conformation; of which a large oval hole, placed at the junction of the dental angular and coronoid bones, affords a strong osteological indication. The organization to which it belongs is as follows:-In many species of crocodile the temporal muscle (the grand motor of the lower jaw in most animals) is scarcely more than a rudiment : and although in the gavial, where the great length of the lever to be acted upon requires an increase of power, this muscle is more developed; still, even here it is but imperfectly displayed. In order to compensate for this deficiency, the masseter, on which the additional functions usually belonging to the temporal muscle thus devolve, re- 
ceives a much greater developement*.-Hence also the coronoid process, the use of which is to receive the main action of the temporal muscle, can hardly be said to exist at all in the crocodile ; while on the other hand, an oval hole is formed in those parts of the lower jaw that give attachment to the masseter, in order to afford a more powerful adhesion. For this purpose, across the oval hole is stretched a strong fibrous membrane, into which, on the outside, are inserted the fibres of the masseter;-and on the inside those of the pterygoid, and internal portions of the imperfectly-formed temporal muscle $t$.

In the other lacertæ,-where the temporal muscle is the great motor of the lower jaw, and the masseter has only its ordinary functions, - the coronoid process is of considerable extent, being formed by a long process of the crescentshaped bone; and there is no large oval hole, but only a sinus in its place, for the insertion of the masseter.

Now the ichthyosaurus appears to possess an intermediate structure in these respects : for although the oval hole, which characterizes the crocodile, is wanting (being represented only by a sinus in the coronoid), yet the coronoid process itself appears to be far less developed than in the other lacertæ, although more so than in the crocodile. It appears also to be formed entirely by a process of the coronoid bone, not by the crescent-shaped bone; although this latter exists on the inner side of the jaw. I am not, however, able to speak with certainty of the termination of the coronoid process, or of the exact outline of the crescent-shaped bone; all the specimens which I have seen having been obscure in these parts. I would particularly refer to fig. 14. PI. XVI. which represents the interior of the lower jaw in the specimen exhibited at large in fig. 8. of the same plate. The bones are here distinguished by the letters employed throughout these papers. $z$ represents the crescent-shaped bone; but its outline is much concealed by investing pyrites. $\Lambda$ bove $x$ there appears

- I have to acknowledge my obligations to a friend, for many of these observations on the parts connected with the temporal and masseter muscles.

+ These characters belong generally to all the recent species of crocodile; but in the fossil species described by M. Cuvier, the oval hole was wanting (see his memoir on fossil crocodiles, p. 20.); and in all the fossil species of this genus which $I$ have myself examined, the temporal fossæ were much more developed than even in the recent gavial. I am persuaded, from every circumstance, that a much nearer approximation to the structure of the other Lacertian genera will be found in the fossil, than in the recent crocodiles : interesting links in the chain of Saurian animals will be thus supplied; and it will probably be found that many of the points in which the ichthyosaurus differs from the recent type, are only instances of its agreement with the fossil. 
to have been a projecting process, broken off from the inner side of the coronoid bone : $y$ is a portion of the articular bone of the lower jaw.

In the left lower jaw of the head figured in PI.XVII. the interior is well displayed ; and this projecting process from the inner side of the coronoid seems distinct. In this specimen, however, the crescent-shaped bone cannct be clearly made out, the jaw being slightly crushed and fractured in this part.

I wish to direct the further inquiries of those who may possess specimens, to these points. Dry and uninteresting as such details must necessarily be, they acquire importance from their connexion with so essential a point as the muscular action employed in moving the lower jaw.

Although in the points which have been mentioned, the angular and coronoid bones (or rather the latter) of the ichthyosaurus approximate more nearly to those of other lacertæ than of the crocodile; yet I have next to notice a configuration, very striking in the character it imparts to the posterior part of the jaw, which brings them back again to the latter type ; namely, their extending, as in the crocodile, so far back, as to cover and conceal on the exterior the whole of the articular bone; whereas in the other lacertæ the articular bone, forming the posterior end of the lower jaw, is displayed for some distance on the outside as well as the inside.

5. The Articular bone.-This affords room for no remark, except in being concealed on the outside, both in the crocodile and ichthyosaurus, as just stated. It may be seen, marked $y$, in the sketch of the inner side of the jaw, fig. 14 . PI. XVI.; and in the left lower jaw of the head, PI. XVII.

6. The Opercular bone,-affords no distinctive characters*, but very closely agrees with that of the crocodile.

On the whole, then, if the lower jaw in the ichthyosaurus is compared with that of the crocodile and other lacertæ, the analogies will stand as follows :The extension of the angular and coronoid bones, so as to cover the articular, renders the posterior extremity exactly like that of the crocodile ; and the furrow carrying the teeth, though strictly speaking sui generis, yet approximates most nearly to the alveolar dental of the crocodile. On the other hand, the perforations for the exterior distribution of the branches of the lower maxillary nerve, closely resemble those in the lacertæ; and the absence of the oval hole is a character of the same kind, though common perhaps to some of the fossil species of crocodile also. The structure of the coronoid process appears to hold an intermediate place.

* This bone is very little developed in some of the lacertæ; but in others it acquires almost as great an extent as in the crocodile. 
Before quitting the lower jaw, I wish to call the attention of the reader to two series of transverse sections, exhibiting the arrangement of its bones, from very perfect specimens. See figures 1 . to 5 . and 9. to 13. Plate XVI.

A similar series was given in the former memoir, already referred to; but had the disadvantage of being made up from different specimens. The present, being deduced from two individuals only, illustrates this subject with more certainty ; since a variation, arising from difference of species or of age, might be suspected in the former instance. The specimens now figured are also remarkably free from compression.

The first of these series (figs. 1. to 5.) is taken from the anterior portion of a very large lower jaw of ichthyosaurus platyodon, in the possession of Mr. De la Beche; of which a lateral view is given in fig. 6 : and the bottom is represented, with its hinder extremities restored, from another specimen, in fig. 7 . The second series (figs. 9. to 13.) includes only the posterior half of the lower jaw, and is taken from the very fine specimen of ichthyosaurus communis belonging to the Oxford collection, which is shown entire at fig. 8. PI. XVI. The section, fig. 4. nearly corresponds, as to the place of the line in which it traverses the jaw, with that marked 13.; and fig. 5. with fig. 12.; so that the slight differences which exist, may be considered as characterizing the different species.

In comparing these with the figures given in the former memoir, Vol. V. Pl. 40. it will be observed, - that whereas in the specimens of I.communis and I. platyodon now figured, the coronoid bone disappears on the outside (being overlaid and concealed by the overhanging flap of the dental) before the similar concealment of the angular bone,-in those formerly figured the angular draws itself up beneath the coronoid, before the coronoid is thus covered up itself. The latter structure is apparently characteristic of the species I. intermedius, and will be seen well displayed in the lower jaws of the beautiful specimen figured in PI. XVII.

Fig. 7. of the sections in the first memoir (Vol. V. Pl. 40.) appears to require correction, where the dental bone, $u$, is represented as ending in a thick knob. An accidental fissure must in this instance have been mistaken for the true suture between the bones, since in every other instance the dental expires in a thin plate.

I would particularly invite attention to the beautiful manner in which these bones appear to be packed and adjusted together in the series now figured.

Another striking contrivance in the structure of this composite lower jaw deserves to be noticed. Where the coronoid is interposed between the dental and opercular, its fibres have a slanting direction; while those of the two latter bones 
are horizontally disposed : thus the strength of the part is greatly increased by a regular diagonal bracing, without the least addition of weight or bulk. A similar structure may be noticed in the overlapping bones of the heads of fish, and in a less degree also in those of the turtle.

IV. Nostrils and Anterior Part of Upper Jaw.-Some general remarks may be added to what has been said in the former memoir on the structure of these parts.

Nature designed both the ichthyosaurus and the crocodile to possess elongated muzzles; but she has in the two instances varied the usual Saurian type, in order to produce this effect in a very different manner. In the crocodile she has given extraordinary length to the maxillary bones; and, removing the nostril from its usual place, transferred it to the extremity of the intermaxillary bones. The reason for this may probably be, that the crocodile lurks for prey near the banks of rivers, with the tip alone of his long snout out of the water. At that point, therefore, the nostril was necessarily placed, to enable him to scent his food. But to the ichthyosaurus, living in the sea, such a position of the organ would have been useless: as in the lizard, therefore, in the monitor, and indeed in most quadrupeds, this opening is placed between the nasal, maxillary, and intermaxillary bones; and the protongation of the snout is principally effected by an unusual elongation of the intermaxillary bones.

The position of the nostril in the crocodile, moreover, gives unusual development to the nerves of the olfactory organ; the sense of smell must therefore be very acute in that animal. But in the ichthyosaurus, the parts connected with the organ being small in their proportions, the sense was probably dull. This has been insisted on as an important distinction between the two genera*.

V. Exe and Orbit.-These parts give rise to no new remarks. The bony plates of the sclerotica present a difference from the crocodile, and an agreement with the other lacertæ.

VI. The Temporal Fosse. - In the head of the crocodile, two fossæ may

* It should be observed, that in the sketches of the head of ichthyosaurus accompanying the first memoir, the posterior end of the intermaxillary bones has been carried somewhat too far back, being made completely to encircle the opening of the nostril ; whereas it should have been confined to the anterior margin of that opening, which is bounded by it; as is the lower margin by the lacrymal, and the superior by the nasal bone. The position of the nostril between these three bones answers to that in the lacertæ. This part is correctly represented in PI. XVII. of the present volume.

VoL, VI. 
be observed on either side the post-orbital part of the head * that is to say, an upper fossa, included between the parietal bone $(m)$, the post-orbital part of the frontal $\left(h^{\prime}\right)$, and the part of the temporal (marked $n$ ), which from its analogies $I$ should wish to designate as the squamoso-zygomatic bone; and a lower fossa immediately beneath the first, included between the post-orbital process of the frontal $\left(h^{\prime \prime}\right)$, and the post-orbital process of the jugal $(c)$; the portion of the temporal which surrounds the cavity of the tympanum and carries the condyle of articulation with the lower jaw, answering to the os quadratum of birds (o); and another bone (marked $p$ ), interposed between the last and the jugal, and considered as another dismemberment of the temporal.

I am obliged to recur to these circumstances, because much confusion has existed with regard to these two fossæ ; the lower fossa having been considered as the true temporal fossa, and the upper as peculiar to the crocodile; whereas in fact the reverse is rather the true representation of the case.

The upper fossæ are undoubtedly the true temporal fossæ. A comparison with the temporal fossæ of the other lacertæ will at once prove this, for both are included by the very same bones; namely, the parietal, posterior frontal, and the squamoso-zygomatic portion of the temporal: the upper branches of the temporal muscle are also attached round the edges of this fossa.

There is much difference in the size of this upper fossa in different species of crocodile. In the Crocodilus sclerops it does not exist at all, the space in which it ought to occur being covered up by the extension of the contiguous bones; in the gavial, on the contrary, it is considerably larger than in other speciest. A friend, possessed of great anatomical knowledge, has pointed out the true cause of this difference. The gavial, having a much longer lever to move in its lower jaw than the other crocodiles, requires a stronger muscular action. The temporal muscle, therefore, which is little employed in the other species, and exists only as a rudiment, (its functions being supplied, as we have already seen, by the masseter, ) is in the gavial more developed, and consequently the temporal fossæ require and receive a greater extension.

The lower fossæ appear also to be subsidiary to the main or upper temporal fossæ, and, perhaps, are also connected with the attachment of branches of the masseter; but $I$ have not seen a clear explanation of the attachment of the muscles in this part.

In the other lacertæ there are no lower fossæ; but the contour of the part

* I have again to acknowledge my obligations to a friend for many important observations on these temporal fossæ.

+ I speak here of recent species : some fossil species of crocodile have this fossa still larger than the recent gavial. 
which these occupy is completely altered, and the lower portion of it is as it were broken through ; those bones which form the inferior margin of these lower fossa being wanting,-namely, the prolongation of the jugal (c) behind the orbit, and the bone $(p)$ between this and the tympanal portion of the temporal, or os quadratum; and the tympanal bone itself being so placed as to hang as it were loosely among the other bones of the head, by its upper portion, instead of wedging itself in among them as in the crocodile.

The temporal fossæ in the lacertæ, on the other hand, answer entirely to the upper fossæ in the crocodile; with the exception already stated, namely, that, in order to give room to a much more powerful temporal muscle, they have a much greater proportional extent.

Having in my former memoir compared the head of the ichthyosaurus principally with that of the crocodile, I at once perceived that the post-orbital holes on the top of the skull of the former animal corresponded exactly, in position, and in the bones by which they are surrounded, with the upper fossa in the crocodile: but as these appeared, in the accounts of the crocodile which I had read, to be considered as peculiar to that animal, I did not carry my researches further. Having since ascertained the true character of these fossæ, as being the principal temporal fossæ, and as answering to those of the other lacertæ, I must of course retract any inferences deduced from having considered this part as peculiarly approximate to the crocodilian type ; for it will be found, in truth, that it presents a slight modification only of the usual position of the temporal fossæ, and indeed agrees more closely with the skulls of other lacertæ than with that of the crocodile; inasmuch as the fassæ are larger than in the crocodile, and the contour of the surrounding bones, especially the forked outline of the back of the parietal bone, is similar in character to the lacertian type; to which, therefore, rather than to the crocodile, the analogies derived from hence must, so far as they go, incline us to refer the present genus.-But when it is considered how much wider variations exist in this part between different species of crocodile (the sclerops for instance and the gavial), the differences between this last species and the ichthyosaurus will not, I think, appear of very considerable weight. In the remaining part of the head we find distinctions of much more obvious and striking importance, which give to its posterior portion a character strongly approximating to the crocodile, and very widely removed from the other lacertæ.

I have not been able to ascertain whether the lower fossi* ${ }^{*}$ of the crocodile

* The fossa, however, connected with the external opening of the tympanal cavity (see the fol. lowing paragraph and Plate XVI.), appears also to have an opening anteriorly (behind $p$ ); and this anterior opening may perhaps represent the fossa in question. 
can be traced in the ichthyosaurus: they may perhaps be covered by the extension of the conterminous bones. But still the general outline is preserved; for this part is not broken into as in the lacertæ, but an intermediate bone $(p)$ occurs, connecting the jugal $(c)$ and the lower part of the os quadratum $(o)$. The analogies of this part of the hear with the crocodile will appear yet more strongly in the following statement.

Vil. Position of the Tympanal Bone, or Os Quadratum, and Parts surrounding the external Opening of the Tympanal Cavity.-The bone analogous to the os quadratum, or that part of the temporal which articulates with the lower jaw and in part surrounds the tympanal cavity, is placed quite loosely in all the lacertæ (as distinguished from the crocodile); being attached only by its upper extremity to the superior or squamoso-zygomatic branch of the temporal $(n)$ at its junction with the mastoid. In the crocodile, on the contrary, it adheres firmly between this bone and all the others in its neighbourhood, being connected with the jugal by the interposed bone $(p)$. In all these features the position of the os quadratum in the ichthyosaurus agrees entirely with that in the crocodile, and differs entirely from its position in the other lacertæ. The effect of this is to give to all this part of the head a contour at first sight strikingly similar to the former, and most completely dissimilar to the latter.

A fossa, evidently connected with the external opening of the tympanal cavity, may be distinctly seen in the head represented fig. 8. PI. XVI. between $o, p$, and $n$; and, although the bones are slightly displaced, may be traced in the head represented PI. XVII.*-It will be seen, on comparison, to agree very nearly with that of the crocodile, being surrounded posteriorly as well as anteriorly by the neighbouring bones; whereas, in the other lacertæ, the posterior inclosure is formed by membranes only. The mastoid process $\left(n^{\prime}\right)$, which completes the inclosure posteriorly in the Ichthyosaurus, appears to be a separate bone: in the crocodile it is united to the squamoso-zygomatic bone $(n)$; in the lacertæ it is separate, but very differently placed.

VIII. Occipitar Bones.-So far as I am able to judge from the inspection of numerous specimens, the structure of the occipital part of the head agrees with

* In this specimen the squamoso-zygomatic portion of the temporal appears to be broken off; and the upper extremity of the os quadratum, together with superior and lateral occipitals, are forced outwards. The mastoid process however $\left(n^{\prime}\right)$ is nearly in its true place.-See the de. scription of the Plates. 
the sketch in the margin; but never having seen the part entire in any single specimen, I have wished to keep this representation distinct from the delineations of actual specimens which accompany this paper ; intending it only to serve as an index to the detached bones represented in the Plates; and offering it

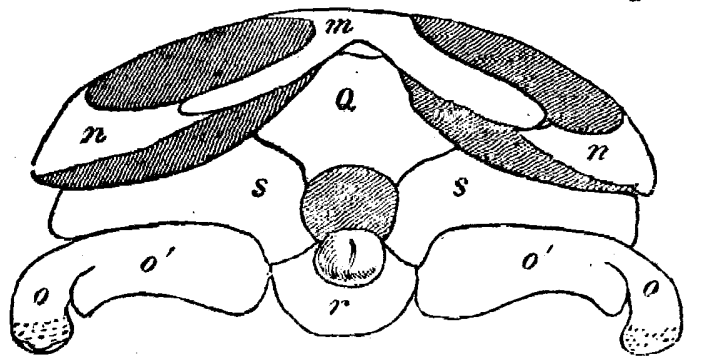
only as an attempt to restore the part conjecturally.

First we may notice the posterior face of the os quadratum ; this bone is well exhibited in the back of the head represented fig. 8. PI. XVI.; and presents the outline given in the annexed sketch. A sort of wing-shaped process $\left(o^{\prime}\right)$ runs back from it towards the inferior occipital $(r)$; but this part is rather obscured by pyrites, and it cannot be clearly ascertained whether this process may not be a separate bone united to $(o)$ by a suture.

The inferior occipital $(r)$, bearing the condyle, is frequently found in a detached state : three figures of it are given in Pl. XX. fig. 2.:-where $a$ is a view of the exterior surface; $b$ is a lateral view; $c$ is a view of the interior surface. It is shown, beneath the temporal bone (here crushed in upon it) in Pl. XVI. fig. 8. ; and close to the posterior part of the pterygoids in the head figured in Pl. XVII.

The superior $(Q)$ and lateral occipitals ( $s s)$ I have only observed in one specimen; namely, the head which is figured in PI. XVII. They are there slightly displaced, but may at once be recognised as surrounding the top and side of the foramen magnum.

The whole configuration of the occipital portion of the head, especially the manner in which it is connected with the os quadratum, bears a much nearer analogy to the crocodile than to the other lacertæ. Some of the separate bones, however, approach more nearly to those of the latter; the superior occipital, for instance, in the crocodile, does not extend low enough down to form the upper margin of the foramen magnum; but in the ichthyosaurus it appears to do so, as in many lacertæ.

IX. Patatal Bones, Prerygoids, \&c.-These parts are exhibited in a very satisfactory manner in the beautiful specimen figured in Plate XVII.

This specimen seems to me clearly to prove that the arrangement of this part agreed in all essential points with the crocodile, and differed from the lacertæ; as will appear by the following detail of circumstances :- 
1. The maxillary bones $(b b)$ are close together, so as to form a solid roof to the mouth.

2. The palatal bones $(e e)$ and internal pterygoids $(f f)$ are likewise close to each other, so as to form a floor below the nasal canal, and thus throw its posterior opening far back.

A greater solidity is thus given to the whole appearance of this part, and the position of the posterior opening of the nasal canal must affect the functions of respiration.

I cannot discover in this specimen traces of the external pterygoids; which were figured in my former paper on the authority of a specimen that was rather dislocated, and might have exhibited deceptive appearances. It now appears, that the narrow form which that specimen assigned to the palatal bones, must have arisen from its presenting only an impression of them where they project into the nasal canal.

It would still be desirable, in order to complete our knowledge of the skull of the ichthyosaurus, to procure a series of sections through its posterior part, such as might lay open the internal arrangement of the bones, especially of the sphenoid. Mr. De la Beche, whose local opportunities in examining specimens are great, will keep this object in view, and the result will at some future time be submitted to the Society.

The notices above given point out all the analogies derived from the osteology of the head. To these it is to be added, that the structure of the humero-sternal part bears decidedly a nearer analogy to the lacertæ than to the crocodile; since the clavicular furcula is wanting in the latter genus.

$X$. Vertebra.-I have only to add to my former remarks on this part of the skeleton, that the atlas and axis agree exactly with the other vertebræ, as is the case in fish. The statement that these parts appeared to resemble the atlas and axis of the turtle, arose from my having taken a mutilated portion of the occipital condyle, in a dislocated specimen, for the inferior portion of the atlas.

XI. Extremities.-A more perfect representation of the paddle than has yet appeared is given in Pl. XX. fig. 1. This will at once show the exact manner in which the series of bones succeed each other. 


\section{PLESIOSAURUS.}

The researches of Mr. De la Beche, during the last year, have not been crowned with the success of meeting an entire skeleton of this new genus; but many important parts have been brought to light.

The first of these is a very perfect dental bone of the lower jaw, which is represented under three points of view in the figures of Plate XVIII , being there one half the natural size. We may with great certainty ascribe this to the plesiosaurus : for it certainly belonged to some animal which had a composite jaw like the Saurians; since the posterior end of the bone thins off too much to have formed part of a single maxilla. Again, in the lias at Lyme, the only vertebræ of size enough to have belonged to such a jaw are those of the ichthyosaurus and plesiosaurus. It is probable, therefore, that it belonged to one of these ; but the dental bone of the former is well known, while that of the latter (till the occurrence of the present bone) had never been found. It cannot with probability be objected that it might have belonged to some third animal so rare that its vertebræ have not yet been met with; for fragments of a similar dental have in other instances been found : so that the suspicion of extreme rarity, which might have attached to a single specimen, is precluded. On the whole then the evidence stands thus :-We find in the same place skeletons of a Saurian animal wanting the jaw, and the jaw of a Saurian animal wanting the other bones; and no other claimants exist for either.

This dental bone resembles that of the crocodile more than that of the other lacertæ. The teeth which, with the exception of one young tooth, have unfortunately been displaced, were lodged in separate alveoli ; on the inner side of those alveoli is a series of small holes, designed apparently for the passage of nerves and vessels (as in the crocodile); and along the outer side of the jaw, dispersed irregularly in small points, are holes for the passage of the branches of the lower maxillary nerve, which is the case in the crocodile also, as contradistinguished from the other lacertæ.

HEad.-Of the head of the plesiosaurus, only a single specimen approaching to completeness has yet occurred; which was discovered by Mr. Thos. Clarke in the Lias of Street near Glastonbury. It is represented in Plate XIX.* This specimen is unfortunately much crushed; but is nevertheless sufficiently perfect to exhibit its most essential osteological characters.

* In this and in the former Plates the same letters have been employed to designate the ana. logous bones. 
These characters, when viewed collectively, present, as might have been expected, an assemblage sui generis. Taken separately, they exhibit partial approximations to the ichthyosaurus, the crocodile, and the other lacertæ; nor is there any part of the structure of this new genus which may not be paralleled from one of these three types. But I should be inclined to pronounce (though not without hesitation) the approximations to the latter class to be most close and important.

In its general contour, the character of its temporal fossæ, and the position of its ossa quadrata, this genus resembles the lacerta iguana, \&c.: but the small size of the nostrils, the conformation of the palatal and pterygoidal parts of the roof of the mouth (so far as the specimen enables us to judge of them), and the dentition, remove it from this type.

It agrees with the ichthyosaurus in the position and small size of the nostrils, and in the structure of the palatal and pterygoidal parts; in which last respect both the one and the other approximate to the crocodilian type; but it differs in the comparative shortness of its snout, which gives an entirely dissimilar character to the whole contour of the head; in carrying its teeth in distinct alveoli instead of a continuous furrow; and in all those points which we have mentioned as peculiarly resembling the proper lacertian type.

The only circumstances of peculiar analogy with the crocodile, are the dentition (as before stated) in distinct alveoli, and the distribution of the holes in the maxillary bones giving passage to the branches of the maxillary nerve.

Like the ichthyosaurus, then, this animal seems in a certain degree to have blended the characters of the lacertian branch of Saurians, properly so called, with those of the crocodile, and to have been in the same manner distinguished from all recent Saurians by an inferior development of the olfactory organs.

I proceed to a more detailed examination of the specimen represented in Plate XIX.-

Dentition.-The teeth are conical, very slender, curved inwards, finely striated on the enamelled surface, and hollow throughout the interior; they most nearly resemble those of the crocodile, but are still more slender : the specimen being obviously a young individual, it is impossible to determine whether the teeth continue hollow in age, nor are there any appearances which indicate the manner in which the secondary replace the primary teeth. The eight anterior teeth are considerably larger than the rest.

Lower jaw. - The dental bone $(u)$, although well exhibited in this head, is yet so much more perfectly displayed in the larger specimen, figured in PI. XVIII. that we have only to refer to our description of that specimen.

The opercular bone may be seen as a lamina lining the interior of the dental. 
The suture dividing the coronoid bonc $(x)$ and the angular $(v)$ may be traced in the posterior part of the jaw. The coronoid process is not visible.

The articular bone $(y)$ seems considerably more developed than in the ichthyosaurus and crocodile, and to approximate more nearly to the corresponding part in the proper lacertian type.

The lower jaw further agrees with the lacertian type, in the absence of the oval hole which characterizes the recent species of crocodiles.

Upper jaw, and sutures of the head.-It is very difficult, from the crushed state of the specimen, to ascertain the exact situation of the sutures dividing the component bones of the head. The intermaxillaries (a) appear to occupy a considerable space in front of the nostrils; the maxillaries $(b)$ to exhibit only a small portion exteriorly. The nostrils are small, and placed as in ichthyosaurus; the sutures dividing the nasal $(k)$, lachrymal $(i)$ and frontal bones $\left(H h h^{\prime}\right)$ are indistinguishable; and the outline of the orbit has been entirely distorted by the compression the specimen has undergone. The jugal bone $(c)$ is tolerably distinct, and the suture dividing it from the posterior frontal $\left(h^{\prime}\right)$ may be traced; the branches of the parietal $(m)$, and the temporal $(n)$ surrounding the temporal fosss, are sufficiently clear. The structure of all these parts closely agrees with that of the lizard, iguana, \&c. The os quadratum ( $o$ ) is suspended as it were by its articulation to the temporal $(n)$, as in the above genera, and not solidly fixed by an insertion among all the neighbouring bones as in the crocodile, and probably in the ichthyosaurus.

Traces of the occipital and sphenoidal bones may be seen, but in a state so much mutilated and distorted, that it is absolutely impossible to form any judgement concerning these parts. Within the left temporal fossa part of a slender cylindrical bone may be observed, which is probably a fragment of the long columnar process uniting the sphenoid to the parietal; a structure peculiarly characteristic of the lacertian type. The palatal and pterygoidal bones are very obscurely shown; we have only ventured to indicate these parts by dotted lines.

The accompanying Plate represents,

Fig. 1. A view of the specimen, placed so as to rest on its upper surface: this exhibits the whole of the right lower jaw, and the jugal and temporal bones and os quadratum of the same side.

Fig. 2. A view of the specimen, placed so as to rest on the lower jaw, and thus exhibiting all the upper part of the head.

Fig. 3. A single tooth, rather magnified, and split, so as to show the interior cavity.

Fig. 4. An attempted restoration of the head, to assist the eye in tracing the connexion of its parts : A. viewed on the side; $B$. viewed from above. The VOL. VI. 
data are sufficient to render this restoration a very close approximation but the sutures between the bones, being in many instances doubtful, are indicated only by dotted lines.

On the whole, then, the manner in which the ribs of the plesiosaurus articulate, throughout, by a single head, to the extremity of the transverse processes of the vertebræ only, - the structure of the humero-sternal parts, - and the characters derived from the head, approximate this animal most nearly to the lacertæ. By its teeth, on the other hand, it is allied to the crocodile : while its small nostrils and multarticulate paddles are features in which it resembles the ichthyosaurus.

In Plate XXI. fig. 1, 2, 3, is represented the posterior portion of the lower jaw of some saurian animal, perhaps the plesiosaurus, found in the lias at Weston, near Bath, by Colonel Birch. With it was found the bone, figures $4,5,6$; probably an humerus, but very different in its contours from those of the plesiosaurus which we had previously met with. Perhaps it may be a new species; but as it probably belonged to the same individual with the jaw-bone accompanying it, we cannot speak with certainty of either.

Colonel Birch has lately procured two specimens, which exhibit the humerosternal parts of this animal in situ. They confirm the place we assigned to these bones, as figured in our former memoir ; but we still wait for more illustrative specimens before we endeavour to figure the whole of this part. At the point of the clavicular furcula there appeared to be a complex apparatus of bones, probably a regular sternum; but this part was too much fractured to be much relied upon. The coracoid bones had a somewhat greater length, from their anterior to their posterior tip, than those before figured; but as they belonged to an animal of much greater size, the proportion may perhaps be modified in age.

Attached to one of these specimens, was a series of vertebræ exhibiting the cervical, dorsal, and lumbar vertebræ in situ : this was important, as confirming the position assigned to those figured in the former paper, which were loose, and had been often deranged; the arrangement assigned to them is however in every instance confirmed by the series now mentioned.

In Plate XXII. are figured an os ilium? fig. 3; an os pubis, fig. 2; and a femur, fig. 1; all found with other bones of the plesiosaurus. From the inspection of specimens in which the humerus and femur have been found together, it appears that they are both much of the same size; so that probably in this animal the difference between the length of the anterior and posterior extremities, observed in the ichthyosaurus, does not exist. 
on the Fossil Genera Ichthyosaurus and Plesiosaurus.

I shall conclude these details by noticing a series of vertebræ discovered in the Kimmeridge clay near Weymouth, and exactly corresponding to specimens found in the same formation in Headington pits near Oxford. They appear to belong to a species of plesiosaurus, as will be seen by comparing them with the vertebræ figured in the former memoir. There is this great difference, however; that in the plesiosaurus of the lias, the length of the side in the cervical vertebræ is greater than in the dorsal; in these the proportions are reversed: the latter are figured in Plate XXII. fig. 4 to 7 , and may be thus compared with the series before given in Vol. V.-

Fig. 4, Plate XXII. of the present communication......... $\}$ with fig. $4 \& 5$, Plate 41, Vol. V.

Fig. $5 \ldots \ldots \ldots \ldots \ldots \ldots \ldots$ with fig. $6 \ldots \ldots \ldots \ldots \ldots$

Fig. $6 . \ldots \ldots \ldots \ldots \ldots \ldots \ldots$ with fig. $7 . \ldots \ldots \ldots \ldots \ldots$

Fig. 8. will be found exactly to resemble the ordinary form of the middle dorsal vertebræ in the plesiosaurus.

These vertebræ are more than three inches in diameter, yet the annular part has not anchylosed to the body.

I cannot conclude these observations without appealing to the reader's indulgence, as well on account of the nature of the subject, as of my own inexperience in the branch of science to which it relates. To the observeractually engaged in tracing the various links that bind together the chain of organized beings, and struck at every instant by the development of the most beautiful analogies, almost every detail of comparative anatomy, however minute, acquires an interest, and even a charm ; since he is continually presented with fresh proof of the great general law, which Scarpa himself, one of its most able investigators, has so elegantly expressed-" Usque adeo $\mathrm{Na}$ tura, una eadem semper atque multiplex, disparibus etiam formis effectus pares, admirabili quâdam varietatum simplicitate conciliat:"-Yet when these very details are reduced to the technicalities of language, and when a perpetual struggle against the difficulty of conveying clear ideas of the relations of form through the medium of words, is to be sustained, they must often unavoidably appear dry and tedious. I need not add how much these difficulties will be increased in the hands of a writer, who must acknowledge that, while intruding on the province of the comparative anatomist, he stands on foreign ground ; and, using almost a foreign language, is frequently driven to adopt an awkward periphrasis, where a single word from the pen of a master would probably have been sufficient. 

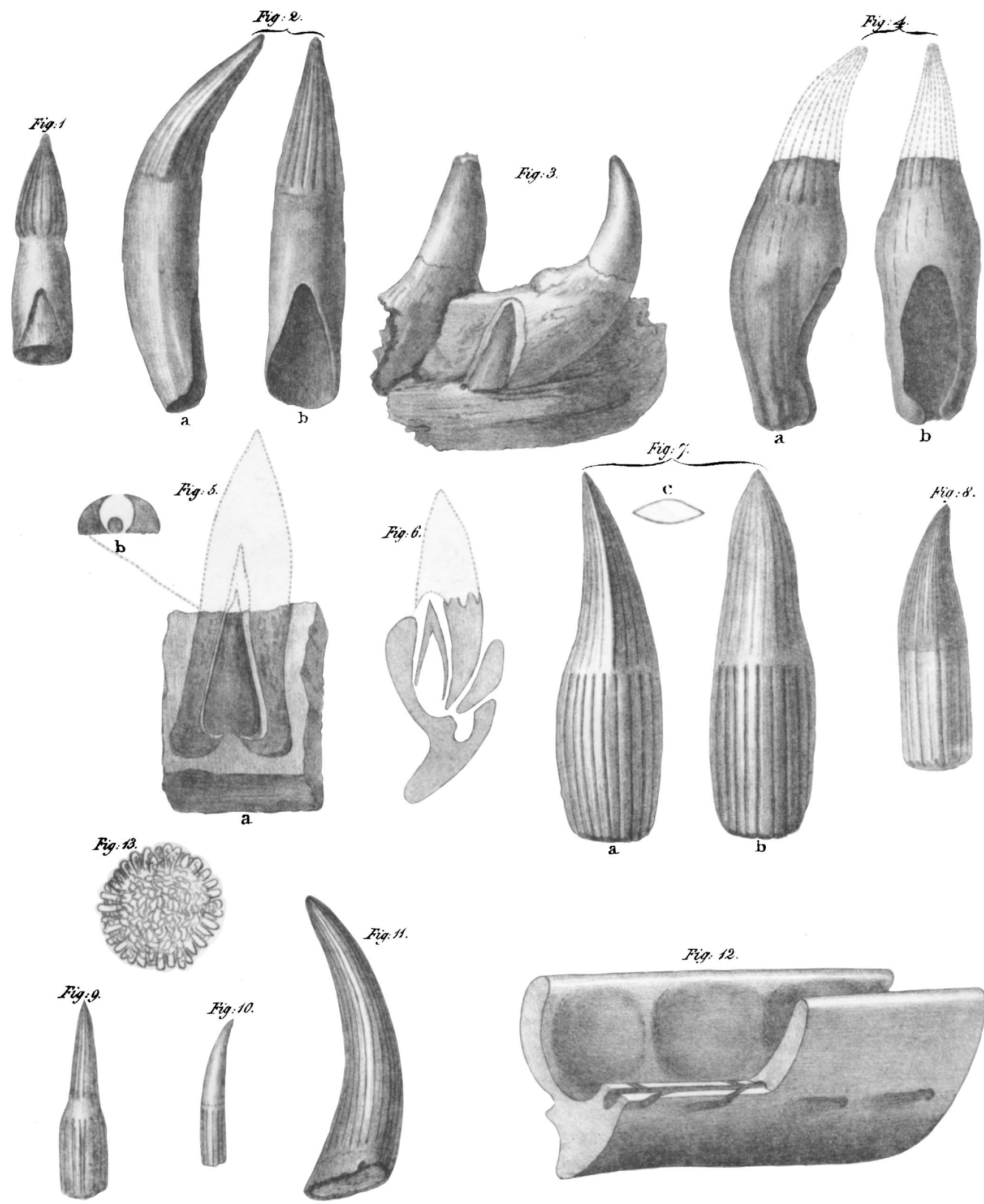

Fig. 12.

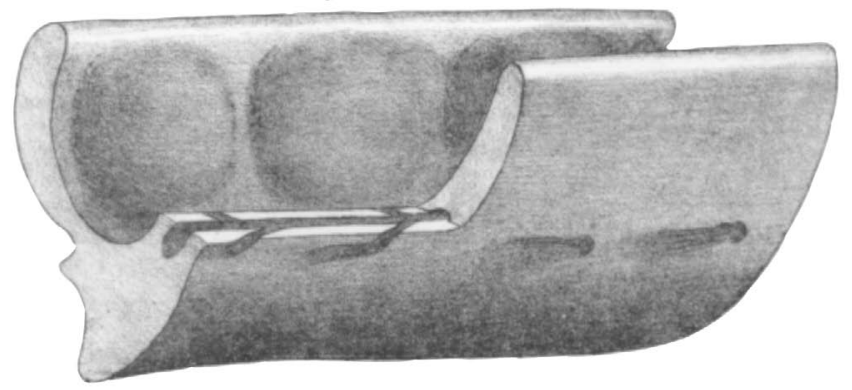



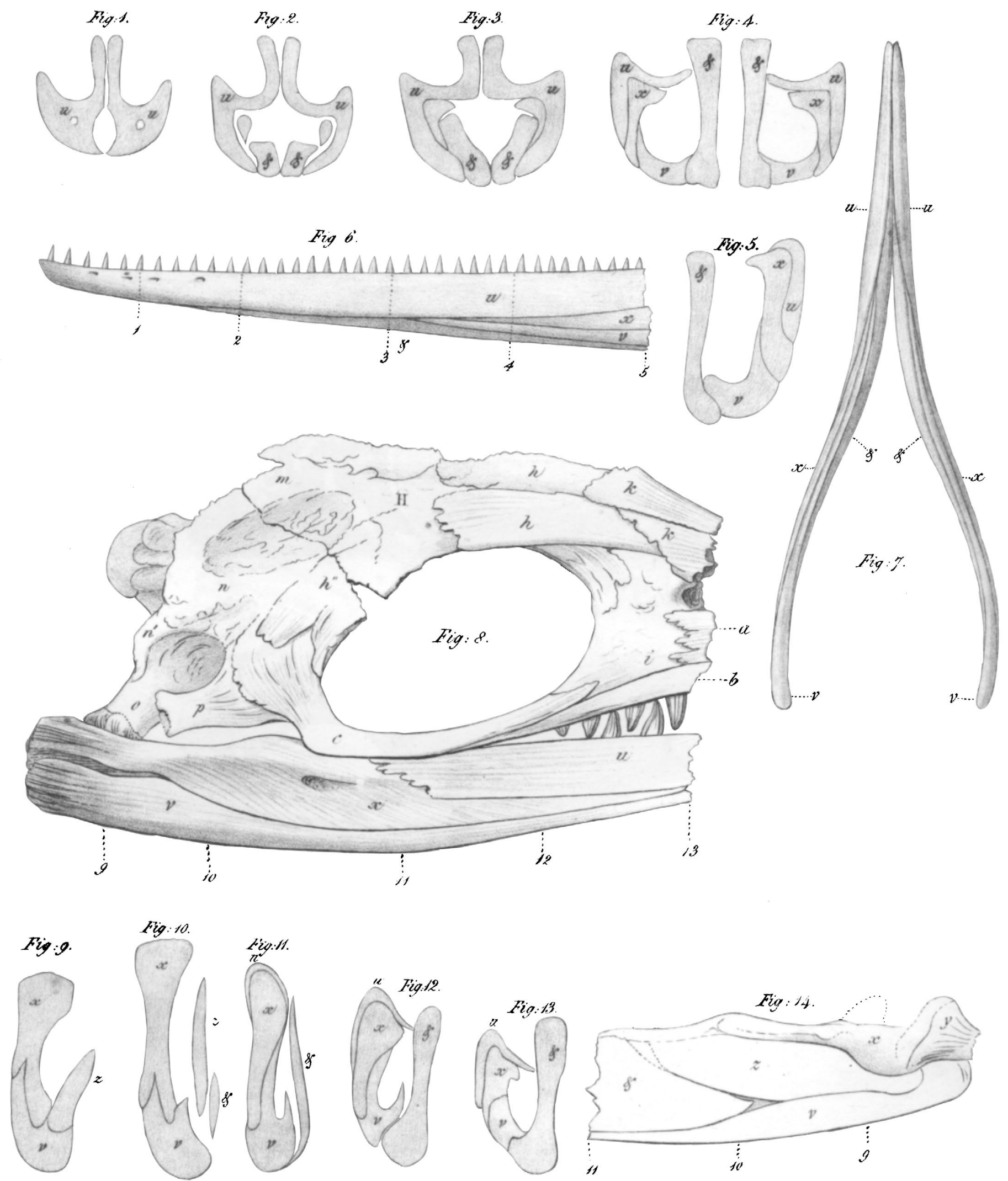


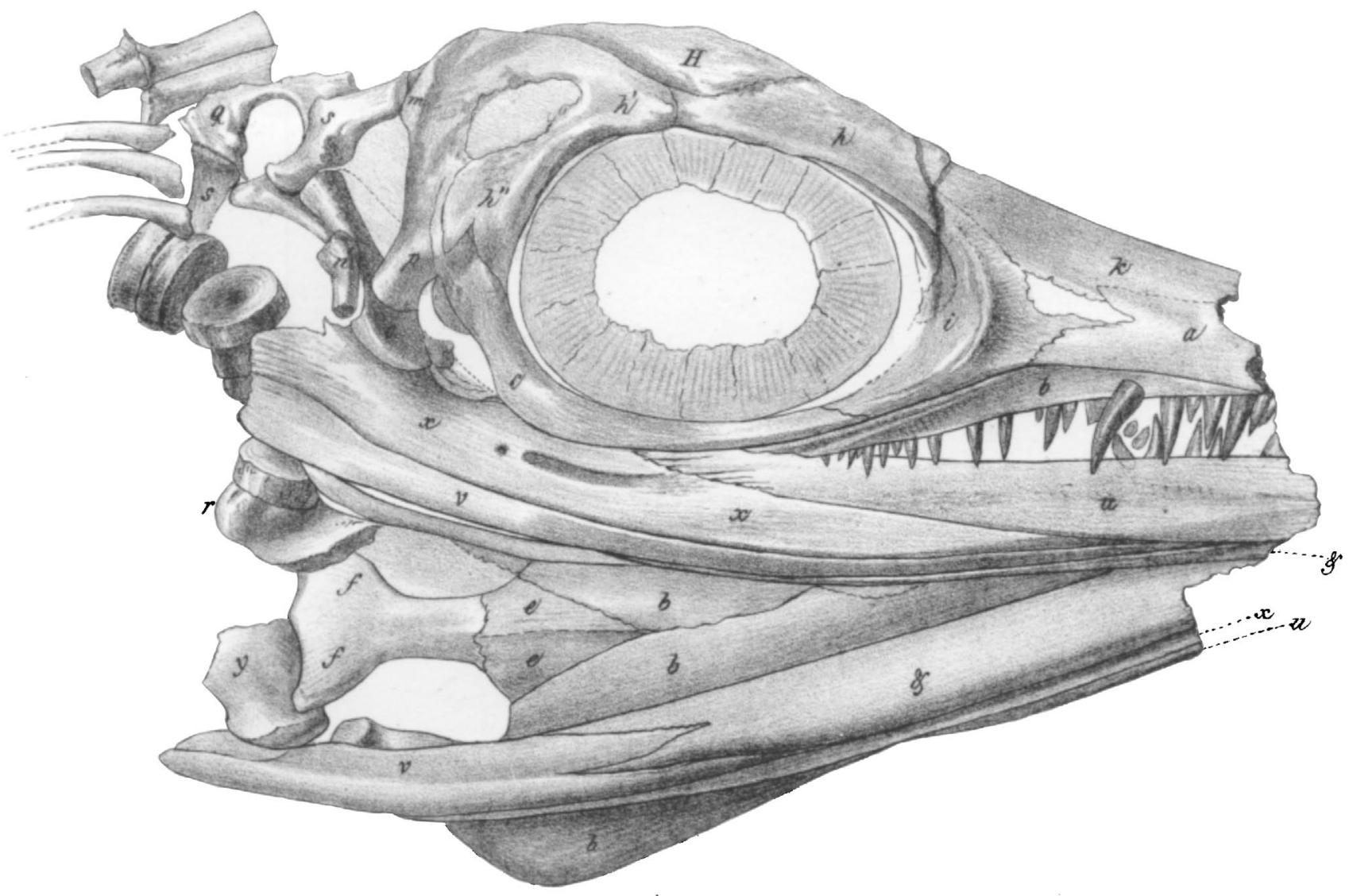




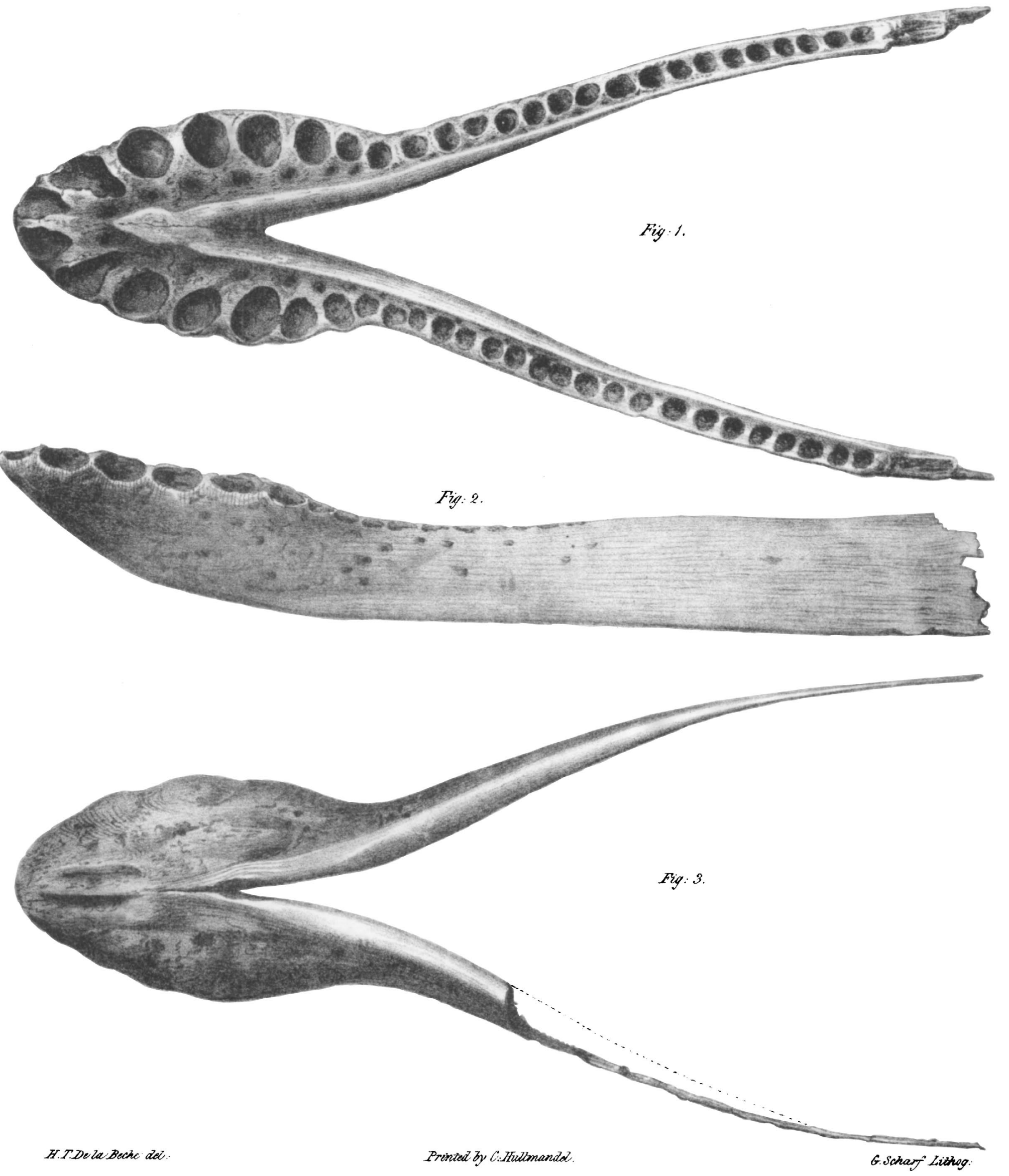



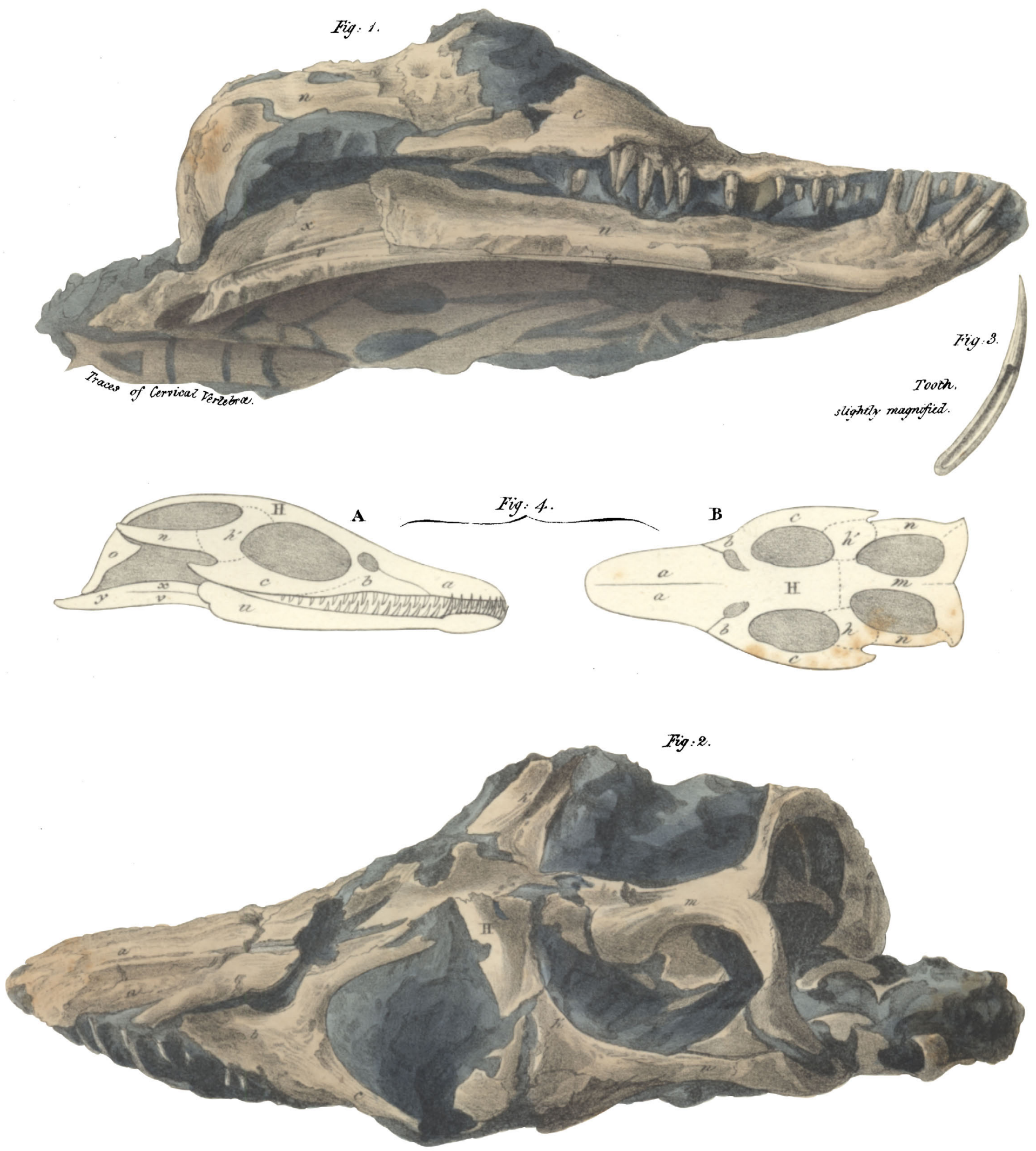
Fig: 1 .
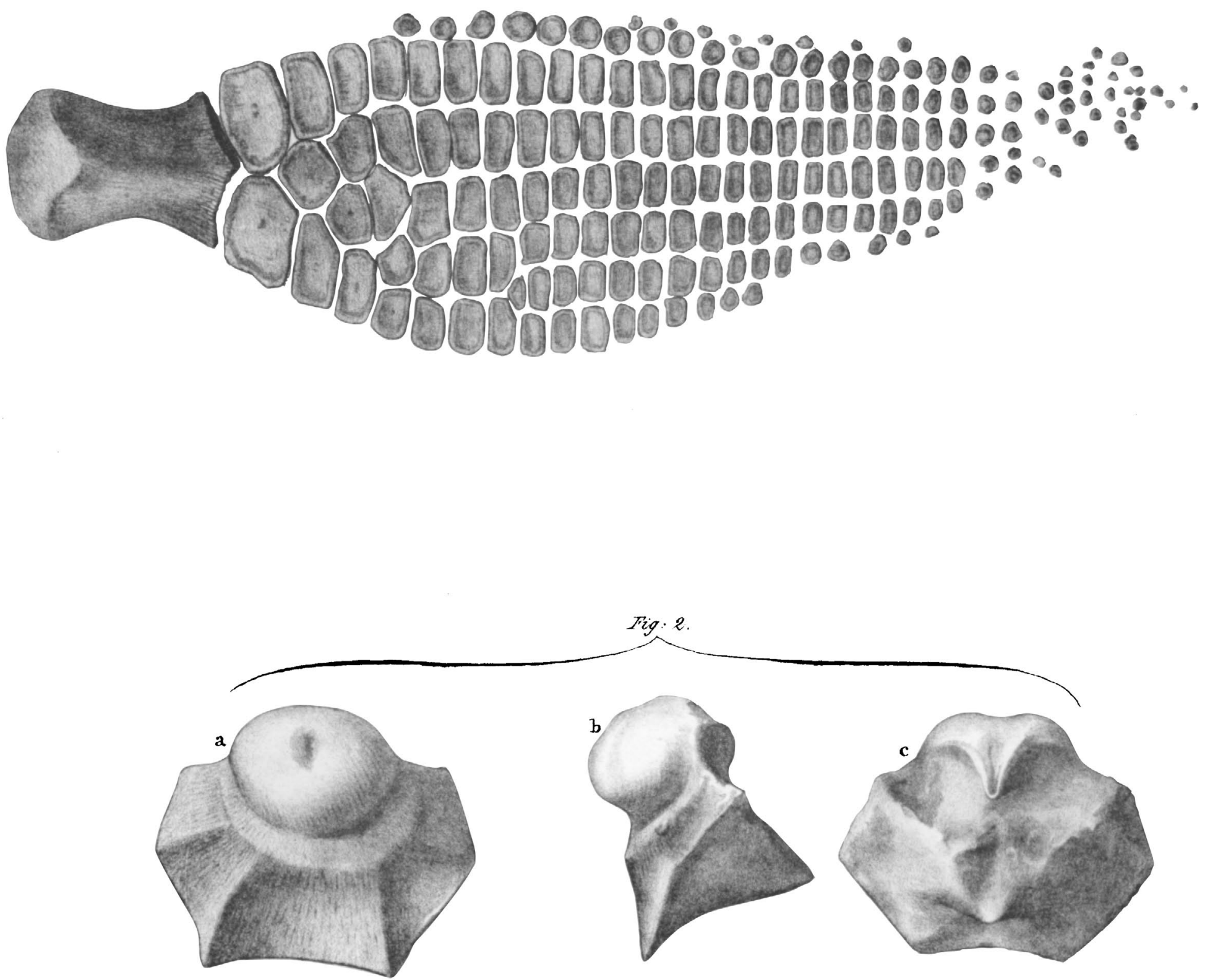

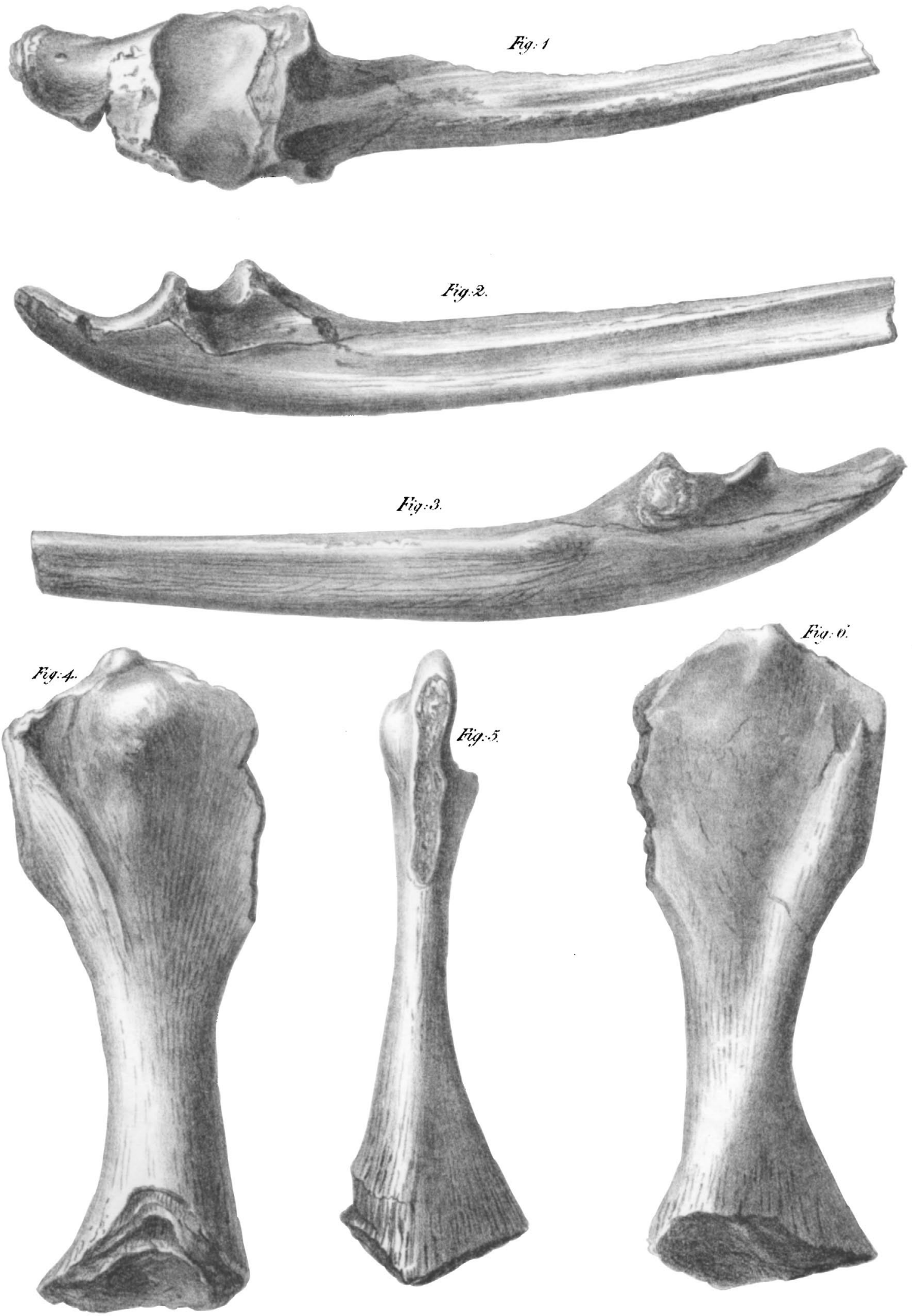

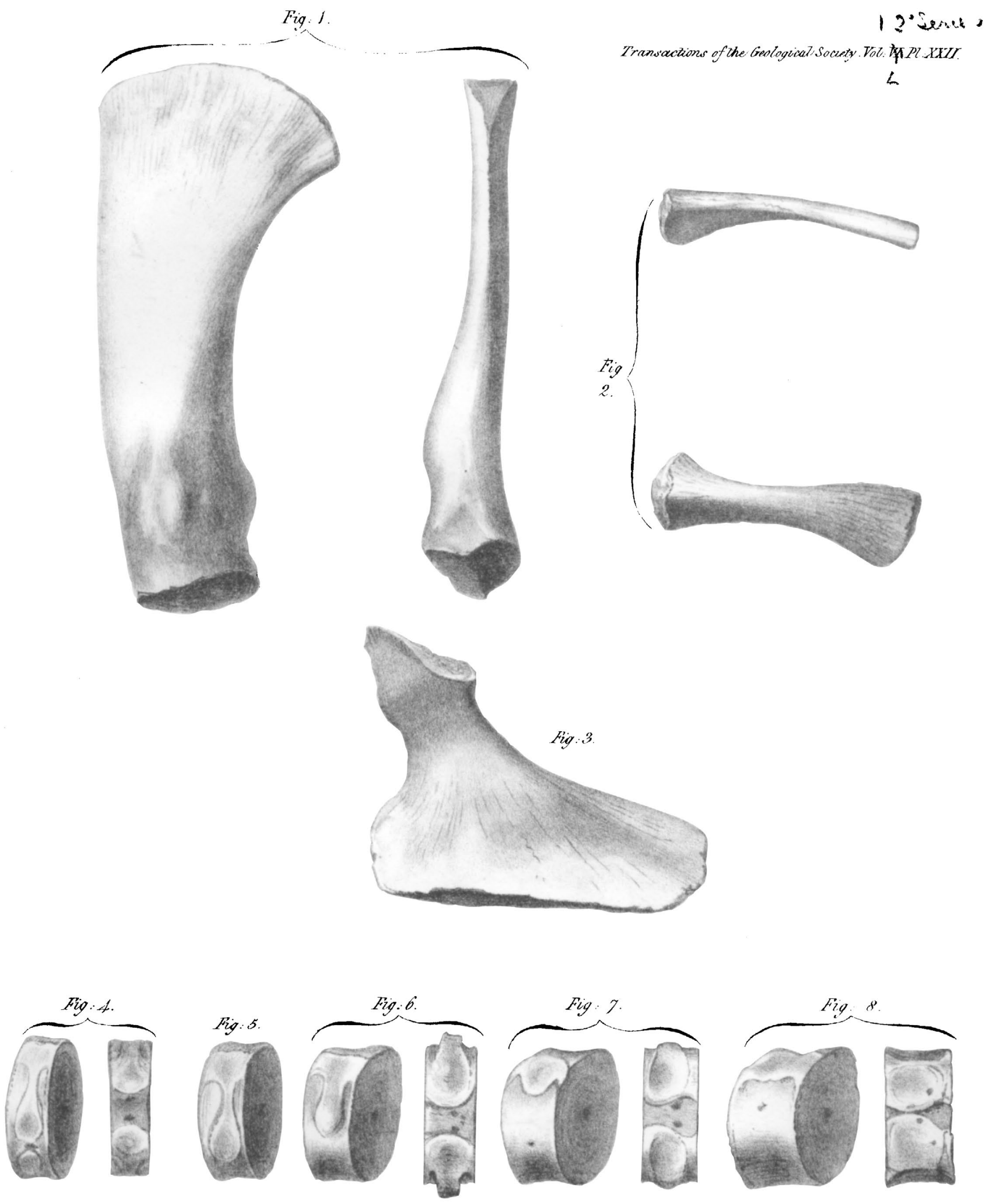